\title{
As transformações na estrutura produtiva internacional e os impactos na indústria brasileira: uma análise a partir da dimensão tecnológica
}

\author{
Transformations in international productive structure and impacts on Brazilian \\ industry: an analysis from technological perspective
}

\author{
Guilherme Gomes', Antônio Carlos Diegues"
}

\begin{abstract}
Resumo
O objetivo desse artigo é analisar as transformações da estrutura produtiva brasileira em perspectiva comparada a Alemanha, China, Estados Unidos (EUA), Japão e México, com ênfase na dimensão tecnológica. Para tal, parte-se da hipótese de que tais transformações devem ser compreendidas como derivadas do fenômeno de constituição de redes globais de produção e crescente deslocamento produtivo para países asiáticos que apresentam baixos custos de produção. Admite-se ainda que processo tem condicionado as possibilidades de desenvolvimento produtivo industrial dos países, inclusive o brasileiro. Como principais resultados, observou-se que a China passou a se industrializar ao receber etapas do processo produtivo manufatureiro mundial, fragmentado em redes globais de produção. Por outro lado, países industrializados como Alemanha, Japão e EUA passaram por um processo de desindustrialização no período recente, definido pela literatura especializada como normal. No mesmo sentido, Brasil e México, passam por um processo de desindustrialização entendido pela literatura como precoce, uma vez que não atingiram um grau de desenvolvimento considerável. Conclui-se que no caso brasileiro, observa-se um atraso tecnológico, principalmente em setores típicos do paradigma microeletrônico, além de se observar um aumento do gap de produtividade que tem levado a economia brasileira a um caminho de falling behind.
\end{abstract}

Palavras-chave: Mudança estrutural; Redes globais de produção; Catching up tecnológico

\section{Abstract}

The aim of this paper is to analyze the transformations of the Brazilian industry in perspective compared to Germany, China, the United States, Japan and Mexico, with emphasis on the technological dimension. It is argued that such transformations should be understood as deriving from the phenomenon of global production networks and increasing production displacement for Asian countries with low production cost. It is also admitted that the process has conditioned the possibilities of industrial development of the countries, including Brazil. As main results, it was observed that China began to industrialize by receiving stages of the global manufacturing process, fragmented in global production networks. Industrialized countries such as Germany, Japan and the USA have gone through a process of deindustrialization in the recent period, defined by specialized literature as normal. In the same sense, Brazil and Mexico go through a process of deindustrialization understood in the literature as precocious, since they did not reach a considerable degree of development. This paper concluded that in the Brazilian case, there is technological backwardness, especially in sectors typical of the microelectronic paradigm, in addition to observing an increase in the productivity gap that has led the Brazilian economy to a falling behind path.

Keywords: Structural transformation; Global production networks; Catching up

\footnotetext{
${ }^{\text {I }}$ Departamento de Política Científica e Tecnológica, Instituto de Geociências

II Univercidade Estadual de Campinas
} 


\section{Introdução}

O presente trabalho busca debater as motivações que tem levado a uma reorganização da indústria internacional e seus impactos na produção e no emprego dos países condicionados pelos efeitos da globalização e da emergência do novo paradigma técnico-econômico baseado na microeletrônica.

No último quartel do século XX observaram-se transformações de natureza técnica e econômica que criaram as bases para o surgimento do paradigma empresarial em rede. Destacam-se as mudanças tecnológicas como a revolução na microeletrônica e a produção modularizada e as de ordem econômica como as liberalizações financeiras e comerciais. Nesse sentido, há uma mudança da empresa moderna capitalista baseada na produção em massa, então denominada Empresa Chandleriana, típica do paradigma fordista, para a Empresa em Rede, típica do paradigma vigente baseado nas tecnologias de informação e comunicação (TICs).

A emergência da microeletrônica e sua aplicação nas atividades produtivas industriais ditaram as novas regras para a produção em escala global no início do século XXI. Por sua vez, as mudanças econômicas intensificaram o processo de mobilização do capital e das empresas em escala internacional, intensificadas no Consenso de Washington. A partir desse cenário, a indústria manufatureira global se modificou e se reorganizou como consequência das transformações associadas às tecnologias da informação e comunicação.

Defende-se a hipótese que a constituição de redes globais de produção tem condicionado um processo de transformação estrutural global e levado a países a passarem pelo fenômeno da desindustrialização (com exceção do leste e sudeste asiático). Esse processo tem direcionado as possibilidades de desenvolvimento produtivo industrial dos países, inclusive o brasileiro. Observam-se transformações de ordem tecnológicas na estrutura produtiva dos países selecionados, evidenciadas por indicadores de valor adicionado (VA) e emprego na indústria de transformação, além da estrutura dos dispêndios em pesquisa e desenvolvimento (P\&D) e pessoal ocupado em atividade de P\&D.

Nesse sentido, o objetivo desse artigo é analisar as transformações da estrutura produtiva brasileira em perspectiva comparada a Alemanha, China, Estados Unidos (EUA), Japão e México com ênfase na dimensão tecnológica da estrutura produtiva desses países selecionados. Especificamente, busca-se analisar o posicionamento brasileiro na indústria global destacando principalmente o grau de distanciamento da indústria manufatureira brasileira em relação à fronteira internacional (estrutura produtiva dos EUA). Justifica-se essa escolha pelos EUA apresentarem configuração produtiva com a maior produtividade da indústria global no período entre 1995 e 2014.

Para atingir os objetivos propostos, organizaram-se estatísticas descritivas para a amostra de países a partir do VA, emprego industrial, exportações, diferencial de produtividade em relação à fronteira tecnológica, além de mostrar a proporção do emprego em atividades de P\&D e dispêndio de P\&D para diferentes setores produtivos dispostos segundo a intensidade tecnológica.

Esse trabalho está organizado em três seções, além dessa introdução e das conclusões. A segunda seção busca recuperar os aspectos teóricos da literatura sobre a reorganização da indústria global em redes, principalmente as transformações associadas ao paradigma das tecnologias da informação e comunicação. A terceira seção analisa de forma breve os impactos da reorganização da cadeia produtiva global que tendem a condicionar ao fenômeno da desindustrialização de maneira generalizada nos países. A seção seguinte procura evidenciar as transformações e efeitos competitivos na dimensão tecnológica da estrutura produtiva de países selecionados, levando em consideração o distanciamento da estrutura produtiva brasileira em relação à fronteira internacional.

\section{Reorganização global da manufatura à luz da emergência de um novo paradigma técnico-e- conômico e da empresa em rede}

A partir das transformações no último quartel do século XX, com o crescente processo de informatização, observou-se a consolidação do paradigma baseado na microeletrônica. A consolidação dos efeitos da microeletrônica que tiveram início na década de $1970^{1}$, possui forte aderência às TICs. Essas transformações passaram cada vez mais a fazer parte das atividades administrativas das empresas, uma vez que os processos e rotinas operacionais passaram a ser informatizados. Esses processos foram importantes no sentido que possibilitaram o gerenciamento dos fluxos informacionais e de conhecimentos essenciais para a gestão descentralizada de uma firma, principalmente em escala global.

A crescente penetração das TICs na indústria, principalmente no setor manufatureiro, possibilitou um aumento da produtividade e maior desempenho econômico, além de reconfigurar o modo de produção em escala global.

Neste sentido, pode-se estabelecer um paralelo entre estas transformações e a noção de desenvolvimento econômico apresentada em (Schumpeter, 1912). Isso porque, segundo o autor, o desenvolvimento difere-se do crescimento

\footnotetext{
${ }^{1}$ Ver Mowery e Rosenberg (2005)
} 
na medida em que é marcado por um processo de destruição criadora que viabiliza a reorganização das atividades produtivas no sentido de se incrementar a produtividade da economia. ,Tal processo seria caracterizado por uma reorganização não linear das atividades produtivas. Ou seja, dada a presença de inovações, a destruição criadora ocorreria necessariamente via mudanças qualitativas através de reorganizações substanciais na dinâmica econômica que caracterizaria o fluxo circular. Deste modo, na definição do autor, o desenvolvimento estaria associado necessariamente à geração de desequilíbrios / saltos qualitativos / recombinação na utilização de fatores, uma vez que é caracterizado pela coexistência entre destruição e criação de atividades econômicas.

É exatamente a partir desta noção de desenvolvimento que este trabalho compreende o advento de um novo paradigma técnico-econômico nos anos 1970 e sua capacidade de transformar a indústria e a sociedade global nos decênios subsequentes.

Esse paradigma, caracterizado pela revolução tecnológica da informação, tem seu epicentro os EUA e se espalhou pela Europa e Ásia (PEREZ, 2010; 2011). Adicionalmente, a base competitiva dos países se modificou, na qual a competitividade tem uma dimensão sistêmica (COUTINHO, 1992).

Como consequência, a indústria foi reconfigurada pela produção de componentes microeletrônicos baratos ${ }^{2}$ (PEREZ, 2010; 2011) e a sociedade passou a ter acesso a produtos com maior conteúdo tecnológico e com menor custo unitário. Além disso, tal reconfiguração permitiu ampliar a difusão da informação através das fronteiras nacionais com maior agilidade e menor custo de processamento.

Nesse sentido, as mudanças nas TICs, que apresentam setores altamente tecnológicos, desempenham um papel importante na economia ao transformarem os processos de inovação. Dessa forma, auxiliam a tornar outros setores mais inovadores e mais produtivos (OCDE, 2000), além de poder proporcionar um crescimento das exportações com maior densidade tecnológica. A partir dessas constatações sobre a revolução tecnológica microeletrônica supracitada, criaram-se as bases e os condicionantes das trajetórias tecnológicas sobre as quais se constituem as recentes transformações organizacionais. Dessa forma, faz-se necessário analisar as transformações na indústria manufatureira levando em consideração as transformações paradigmáticas recentes.

Os investimentos em TICs têm um papel importante na contribuição para o aumento do crescimento econômico e do crescimento da produtividade do trabalho, além de tornar mais estreitas as ligações entre as estratégias empresariais e o desempenho produtivo. Vale ressaltar que, além da contribuição para o aumento da produtividade, as TICs geram um efeito transbordamento (spillovers) por meio de externalidades de redes que ampliam a produtividade de forma geral (OCDE, 2000).

As transformações ocorridas na estrutura produtiva mundial levaram ao redirecionamento da produção às redes globais de valor e a um novo modelo de gestão organizacional. Esse processo está associado ao paradigma técnico-econômico baseado na microeletrônica e a nova forma de gestão empresarial baseado na lógica de maximização do valor acionário.

Nesse cenário, as transformações observadas no último quarto do século XX podem ser caracterizadas por suas naturezas técnica e econômica. Em conjunto, criaram as bases para o surgimento da empresa em rede, que reconfigurou as estratégias globais de produção, gestão e inovação empresarial. As mudanças de natureza tecnológica, no período, podem ser caracterizadas pela revolução da microeletrônica e pela consolidação das técnicas de design, de produção e de inovação modularizada.

Segundo Ernst e Kim (2002), a globalização tem alterado a dinâmica competitiva industrial, além de facilitar as trocas de informações em nível global. Além disso, os avanços na microeletrônica possibilitaram a criação de oportunidades para aprendizagem organizacional e a transmissão de conhecimentos entre as organizações e através dos países. Os autores afirmam que as redes de produção global "têm atuado como um catalisador para a difusão do conhecimento internacional" (ERNST e KIM, 2002, p.1418).

Como lembra Sturgeon (2002), o paradigma dominante, observado até meados da década de 1980, é característico da estrutura da "empresa moderna" descrita por Alfred Chandler (1990) e considerado o modelo de organização industrial e de desenvolvimento econômico, que tem sua gênese nos Estados Unidos (STURGEON, 2002). Outra importante reconfiguração das atividades de ordem técnica nas empresas transnacionais, em escala global, é o desenvolvimento de modelos de produção e de inovação organizados a partir do princípio da modularização (ou descentralização). Dentro desse cenário, Sturgeon (2002) afirma que a empresa passa a organizar seus processos a partir da constituição de redes de produção modulares, de modo a dar origem àquilo que ele denomina de novo modelo americano de organização industrial.

Em paralelo a essas características de viabilidade técnica, diversas transformações de natureza econômica impulsionaram o surgimento das redes globais de produção e inovação. Em meio ao colapso do regime de Bretton

\footnotetext{
${ }^{2} \mathrm{O}$ novo conceito industrial associado à revolução tecnológica da informação foi redefinido pela introdução de novas tecnologias ou novos tipos de indústrias (setores), além de observarem transformações em sua infraestrutura. A produção de computadores, software, telecomunicações, instrumentos de controle, biotecnologia auxiliada por computadores e novos materiais são características da revolução microeletrônica (PEREZ, 2010; 2011)
} 
Woods, observou-se uma intensificação da liberalização dos fluxos financeiros e da redução das barreiras comerciais, liberalização das políticas de investimento direto externo e privatizações. De fato, estava-se diante de um modelo neoliberal que iria repercutir severamente nas economias da periferia capitalista, nas décadas de 1980 e 1990.

No Brasil, o último quartel do século XX é marcado pela da crise da dívida da década de 1980, que levou a desorganização da economia brasileira, com estagnação e hiperinflação. No âmbito das relações Estado-Mercado destaca-se o fim do nacional-desenvolvimentismo seguido de reformas liberais posteriores, que se intensificaram na década de $1990^{3}$.

Os efeitos liberalizantes proporcionaram uma redução dos custos das transações internacionais, além de ser observado um grande aumento do volume da liquidez internacional. Nesse sentido, as grandes corporações globais, então denominadas de network flagships, foram as mais beneficiadas ao proporcionar a especialização local, a terceirização e facilitar a mobilidade espacial das empresas ${ }^{4}$.

Ademais, o último quartel do século XX foi marcado pelo avanço da commoditização do complexo eletrônico ${ }^{5} \mathrm{e}$ da integração produtiva em direção ao sudeste asiático e num momento posterior pela emergência da China como potência manufatureira, que intensificou o acirramento da concorrência em escala global. Os avanços na microeletrônica e os processos de modularização da produção, conjugados aos avanços das políticas de desregulamentação e liberalização econômica, intensificaram o processo de globalização do capital.

A partir desse cenário supracitado, cumpre-se destacar a estrutura da empresa Chandleriana ${ }^{6}$, que está organizada em torno do capital acionário, cujo papel principal é a geração de enormes receitas, acumulação dos lucros e reinvestimento na própria estrutura produtiva (CHANDLER, 1990). Lazonick (2010) afirma que as empresas visam transformar os recursos produtivos em bens e serviços que são capazes de gerar enormes receitas para as empresas. Segundo o autor, estas se concentram normalmente, segundo a teoria da firma, em três atividades genéricas de negócios: estratégica, organizacional e financeira.

Lazonick e O'Sullivan (2000) observam que poucas grandes empresas, na década de 1980, dominavam a economia dos Estados Unidos. O resultado dessa dominância pode ser caracterizado pelo acúmulo de enormes receitas, ao longo de décadas. Associado ao processo de liberalização financeira surge o modelo de gestão baseado na lógica da maximização do valor acionário por meio do qual, segundo os autores, a empresa "passou a comandar o direcionamento dos recursos corporativos não mais a partir da lógica vigente na golden age do capitalismo de 'reter e investir' mas sim a partir de uma nova orientação caracterizada pelo movimento de 'downsize e distribuir'" (LAZONICK e O'SULLIVAN, 2000, p. 18).

Como observa Lazonick (2011), há uma mudança organizacional da empresa baseada em "reter e reinvestir" (empresa Chandleriana) para "downsize e distribuir" (empresa em rede), que direciona ao "downsizing" (enxugamento) das grandes corporações estadunidenses. Desse modo, as empresas passaram a construir redes de produção desverticalizadas e geograficamente dispersas. Nesse sentido, a tendência global das empresas líderes é a de concentrarem seus esforços em competências centrais a empresa, como pesquisa e desenvolvimento (P\&D) e marketing, que possuem maior valor agregado e desverticalizar a produção com transferência para parceiros (outsourcing) (GEREFFI, HUMPHREY e STURGEON, 2005).

O quadro 1 sintetiza as informações sobre os dois modelos de organização industrial discutidos nessa seção, os modelos multidivisional, típico do paradigma fordista de produção em massa e o modelo empresarial em rede associado ao paradigma das TICs. Destaca-se que as atividades estritamente produtivas (manufatura) na forma organizacional da empresa em rede apresenta-se de maneira desverticalizada com produção localizada em regiões periféricas de baixo custo, enquanto que no modelo multidivisional a manufatura está integrada hierarquicamente aos moldes da firma.

De acordo com Ernst e Kim (2002), a principal função das redes é fornecer acesso rápido e de baixo custo a recursos, capacidades e conhecimentos que são complementares às competências essenciais da empresa. Os autores afirmam que esse fenômeno ocorre cada vez mais rápido sobre a dispersão geográfica da produção, porém espacialmente aglomeradas em regiões especializadas de baixo custo. Destacam-se as regiões asiática (Coreia do Sul, Taiwan, Singapura, China, Malásia, Tailândia e Índia), Europa periférica (Irlanda, Europa Central e Oriental e Rússia) e na América Latina (Brasil, México e Argentina).

Nesse sentido, a globalização alterou a dinâmica competitiva industrial das nações, uma vez que se observam mudanças no padrão de comércio internacional a partir de um aumento expressivo das importações dos países desenvolvidos, elucidando o deslocamento da produção e exportação para as novas economias industrializadas (países em

\footnotetext{
${ }^{3}$ Ver Carneiro (2002).

${ }^{4}$ A liberalização facilitou a entrada no comércio por meio de licenciamento, subcontratação, franchising (especialização local); proporcionou um melhor acesso aos recursos e capacidades externas que uma empresa necessita para complementar as suas competências centrais (outsourcing); além de reduzir as restrições para uma dispersão geográfica da cadeia de valor (mobilidade espacial) (ERNEST e KIM, 2002).

5 Padronização da produção de partes, peças e componentes a partir de uma "arquitetura modular".

${ }^{6}$ Moderna empresa capitalista, multidivisional, organizada em torno da sociedade de produção, consumo e distribuição em massa.
} 
desenvolvimento). Essa mudança é o ponto central para o que Gereffi (1999) denomina de “milagre asiático”. Em um período mais recente, a China passa a receber etapas do processo produtivo global e se firma como workshop of the world.

Dentro desse contexto da nova reorganização produtiva global com o surgimento da empresa em rede, que tem transformado o modelo de organização industrial, e pelo acirramento da concorrência asiática, surge um novo debate acerca da desindustrialização global. Observa-se que, de um lado, as economias industrializadas, perdem a capacidade de geração de empregos industriais, e de outro, as economias em desenvolvimento recebem as etapas do processo produtivo manufatureiro, que em resposta faz com que o emprego industrial aumente nesses países (principalmente países asiáticos).

Quadro 1 - Síntese comparativa entre os modos de organização das firmas multidivisional e em rede, paradigmas e formas de gestão financeira

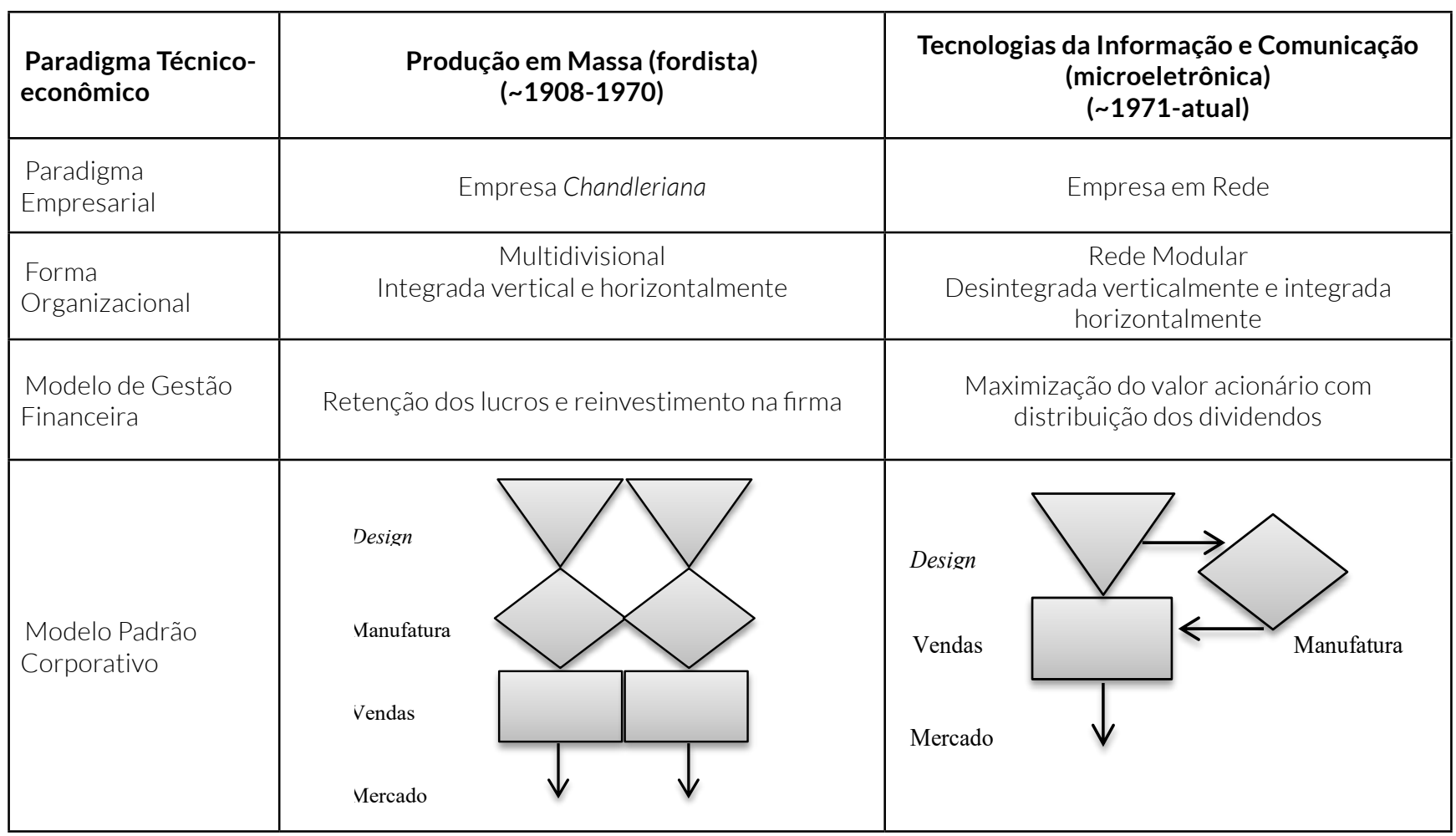

Fonte: elaboração própria com base em Freeman e Perez (1988); Sturgeon (2002); Lazonick e O’Sullivan (2000); Perez (2010)

\section{Os impactos da reorganização da cadeia produtiva global no fenômeno da desindustrialização}

Essa seção busca analisar os impactos da reorganização da cadeia produtiva global nas transformações das estruturas produtivas dos países selecionados. Busca-se verificar se, em paralelo ao movimento de downsize e deslocalização das atividades produtivas em direção à países asiáticos que apresentam baixos custos de produção, haveriam indícios de uma tendência de desindustrialização nos países da amostra que foram afetados por este fenômeno.

Nesse sentido, compreende-se que o papel do setor industrial, principalmente a indústria de transformação, é de extrema importância para o desenvolvimento dos países, uma vez que o setor tem maior potencial de espraiamento de produtividade para os demais setores da economia. Para exemplificar esse ponto, o relatório da European Comission (EC) de 2013 afirma que embora o peso da produção na economia dos países da Zona do Euro esteja perdendo espaço em favor dos serviços, o setor manufatureiro apresenta-se cada vez mais como um setor fundamental para o desenvolvimento econômico dos países (EC, 2013). Por sua vez, o relatório da United Nations Conference on Trade and Development (UNCTAD) reafirma a importância do papel da indústria manufatureira na promoção do crescimento e do desenvolvimento econômico sustentado (UNCTAD, 2016). Nessa perspectiva, convenciona-se também nos dois estudos a importância do papel ativo das políticas governamentais para o crescimento dos países.

Assim sendo, o gráfico 1 apresenta as evidências do fenômeno a partir da variação em pontos percentuais (pp) da participação do VA industrial no PIB entre 1995 e 2014. Observa-se que todos os países e grupo de países apresentaram variações percentuais negativas, com exceção da Alemanha que permaneceu estável. O Brasil destaca-se 
no período com a maior queda da participação do VA da indústria de transformação no PIB do país. As menores quedas foram observadas para o México e o Japão e as maiores para Brasil e EUA, no período analisado. Esses resultados trazem evidências de uma possível desindustrialização generalizada, inclusive para países do leste e sudeste asiático. Entretanto, não se pode concluir a partir da análise singular do VA e somado a isso, a mudança no emprego industrial dos países deve ser verificada.

As mudanças nos padrões estruturais pela ótica do emprego são apresentadas pelo gráfico 2, o qual apresenta a participação do emprego industrial no emprego total da economia de países selecionados no período de 1995 a 2014. Os dados são da Organização Internacional do Trabalho (OIT), agência das Nações Unidas para o tratamento das questões laborais no mundo.

Gráfico 1 - Variação em Pontos Percentuais da Participação do Valor Adicionado da Indústria Manufatureira no PIB, países e grupos de países selecionados, 1995-2014

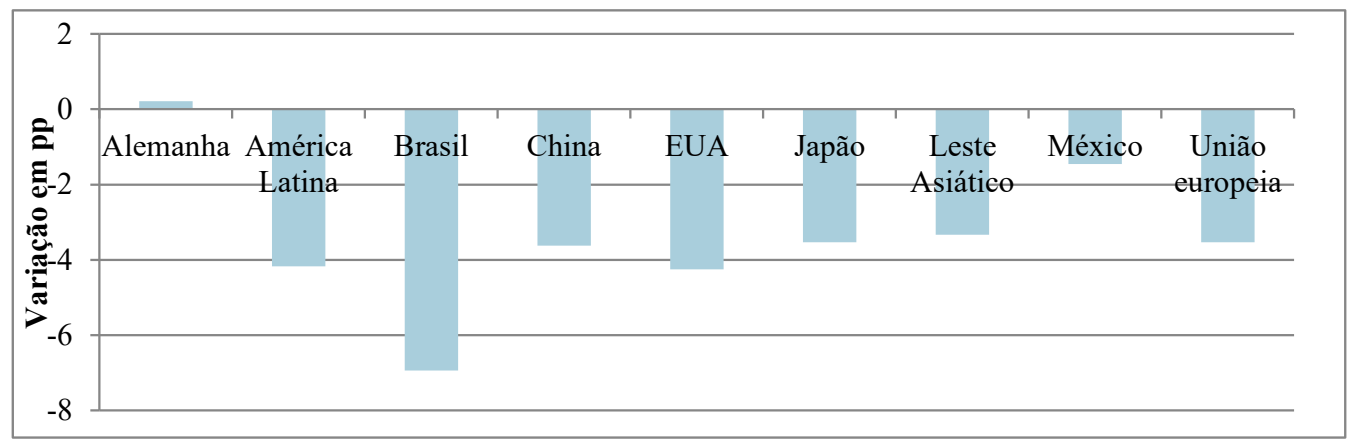

Notas: 1) América Latina e Leste Asiático são cconsiderados somente países em desenvolvimento; 2) Disponibilidades dos dados para Estados Unidos (1997-2013), China e Leste Asiático (1995-2013)

Fonte: Elaboração própria com base nos dados do Banco Mundial

Constata-se que o setor industrial de países desenvolvidos segue tendência de queda na participação de empregos, uma vez que Alemanha, Japão e EUA apresentaram variações percentuais negativas no período entre 1995 e 2014. Ao lado disso, nos resultados paralelos dessa pesquisa encontrou-se que há um movimento de maneira generalizada no aumento da participação do emprego em setores de serviços tanto em países desenvolvidos quanto em países em desenvolvimento. A China foi o país que apresentou as maiores transformações estruturais no período, com maior variação negativa no setor de agricultura e maiores incremento do emprego nos setor industrial (7,2 pp) (Gráfico 2).

Os resultados da perda de participação do emprego industrial em países desenvolvidos estão em conssonância com a literatura. Parece haver um movimento generalizado de desindustrialização desses países, uma vez que se observaram quedas nas participações do VA da indústria manufatureira no PIB e quedas na participação do emprego industrial no total da economia. A perda da participação do emprego industrial nos EUA é devida ao fenômeno da maximização do valor acionário que tem reconfigurado as indústrias estadunidenses, atreladas ao paradigma organizacional da empresa em rede, cujas indústrias deixam as atividades estritamente produtivas e concentram-se em serviços industriais.

Gráfico 2 - Mudança Estrutural do Emprego Industrial, países selecionados, variação em pontos percentuais, 19952014

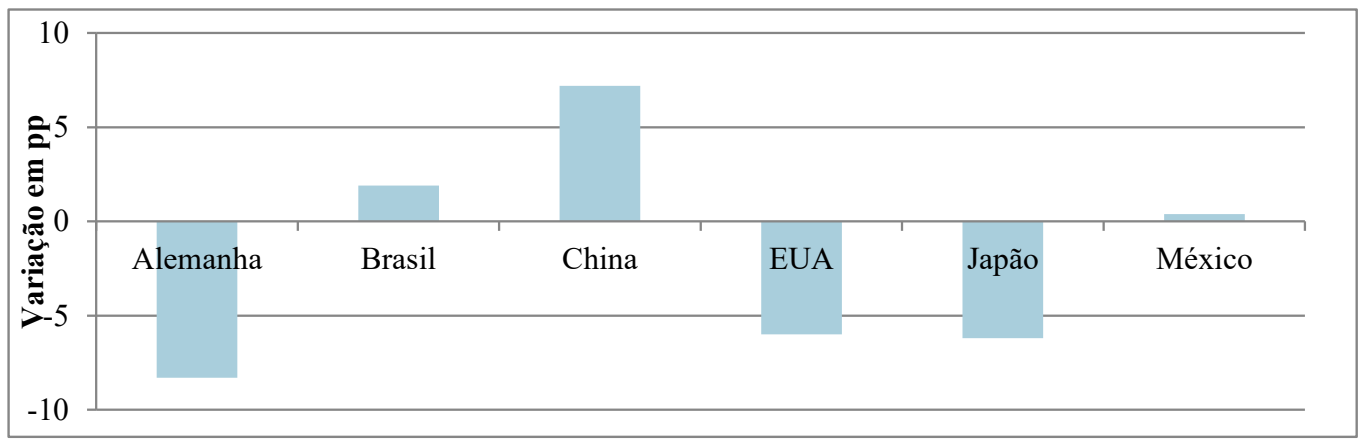

Nota: Os dados são de outubro de 2013, assim os dados para 2014 são uma projeção feita pela OIT Fonte: Elaboração própria com base nos dados da Organização Internacional do Trabalho - OIT/ONU 
De acordo com o estudo da EC, quase todos os países seguem um padrão muito semelhante de mudança estrutural. Quando um país inicia um processo de desenvolvimento, apresentam-se quedas da participação no emprego e no VA nacional em relação ao total da agricultura. Em resposta, há um rápido aumento da quota de produção industrial e de serviços (EC, 2013). Ademais, quando os países atingem maturidade industrial e certo alto nível de renda per capita as economias apresentam perda da participação industrial no PIB e no emprego em favor do setor de serviços. Esse fenômeno pode ser denominado de "desindustrialização normal".

Arend (2015) lembra que economias em desenvolvimento como a China, Índia e Coreia do Sul passaram por um processo de industrialização no período recente ${ }^{7}$, ao passo que Brasil e México apresentaram uma "desindustrialização precoce" e economias desenvolvidas, como EUA e Japão, uma desindustrialização "natural" ou normal".

No entanto, o fenômeno da desindustrialização é complexo e não consensual na literatura especializada sobre o tema. É notório que a mudança estrutural pela ótica do VA e do emprego industrial trazem evidências de uma possível desindustrialização. A utilização do indicador de emprego industrial é feita a partir do trabalho de referência de Rowthorn e Weels (1987, p. 5). Ainda, Tregenna (2008) defende que

ao invés de definir desindustrialização em termos de uma simples dimensão de queda de participação da manufatura no emprego total, assim como na literatura corrente, nós propomos que a desindustrialização poderia ocorrer quando existe um declínio sustentado em ambas a participação da manufatura no emprego total e a participação da manufatura no PIB (TREGENNA, 2008, p. 459, itálicos no original).

De acordo com Palma (2005, p. 4) a queda do emprego industrial pode estar associada ao resultado de uma nova divisão internacional do trabalho. Além disso, o autor argumenta que "o declínio é consequência do rápido aumento de produtividade (pelo menos em alguns setores) na indústria trazido pela propagação do novo paradigma tecnológico de microeletrônicos (esse teria sido um caso da nova tecnologia tender a produzir 'crescimento de desempregados')".

Dessa forma, indica-se que os dois movimentos apresentados são relacionados e dependentes. Observa-se que as transformações paradigmáticas se refletem nas modificações da estrutura produtiva dos países. Entretanto, a análise exclusiva desse indicador não revela o padrão de desindustrialização de países desenvolvidos, de um lado, e o padrão de industrialização de países em desenvolvimento, de outro. O processo se deve a uma multiplicidade de fatores e que precisam ser analisados com cautela.

A próxima seção traz evidências dos efeitos causados na estrutura produtiva brasileira em perspectiva comparada a países selecionados na dimensão tecnológica. Visto que os países apresentaram movimentos de perda da participação do VA e do emprego industrial, busca-se demonstrar o grau desses impactos na estrutura produtiva dos países, a partir da leitura sobre a reorganização da estrutura produtiva global.

\section{Uma análise comparativa das transformações na dimensão tecnológica da estrutura produ- tiva brasileira e de países selecionados}

Para analisar as mudanças na dimensão tecnológica da estrutura produtiva estudar-se-á o processo dinâmico e estrutural da indústria de transformação brasileira nas duas últimas décadas comparado a Estados Unidos, Alemanha, Japão, China e México.

Utilizam-se dados da UNIDO (United Nations Industrial Development Organization) para mensurar indicadores que capturam aspectos na dimensão tecnológica da estrutura produtiva da indústria manufatureira brasileira e de outros países selecionados. O primeiro aspecto objetiva analisar a distribuição da estrutura industrial e como ela está evoluindo segundo os setores e grupos de setores nos diferentes países analisados. A dimensão estrutura revela o modo como estão organizadas as atividades produtivas industriais dos países e por setores de acordo com a intensidade tecnológica. Sendo assim, avalia-se a evolução do efeito por meio do número de empregados na indústria e pela composição do VA. Eventualmente, analisa-se a produtividade do trabalho revelando o grau de distância da produtividade dos países em relação à fronteira. Por fim, são considerados a estrutura de P\&D dos setores e os esforços tecnológicos (mensurado por meio da intensidade de pessoal ocupado em P\&D na indústria de transformação).

Destarte, a partir das informações do gráfico 3 pode-se analisar o VA da indústria em paridade do poder de compra (PPP), o qual evidencia o grau de proximidade dos países diante da economia dos EUA (considerada fronteira internacional). Observou-se que a China ultrapassou o Japão, nos anos 2000, e em 2006 os EUA, e desde então passa a ser o país a apresentar o maior VA industrial dentre os países analisados. O VA chinês destacou-se por apresentar grande e rápido crescimento no período analisado, que cresceu 656,4\% entre 1995 e 2007, com crescimento médio

\footnotetext{
${ }^{7}$ Arend (2015) faz uma análise para vários países no período entre 1980 e 2011.

${ }^{8} \mathrm{O}$ processo de desindustrialização destas economias pode ser entendido como "natural”, pois no momento em que a participação percentual da manufatura no PIB cai abaixo de $25 \%$ do PIB, e de forma sustentada, em todos os casos o nível de renda per capita situava-se ao redor de US $\$ 20$ mil (AREND, 2015, p. 25).
} 
anual de $18,4 \%{ }^{9}$. Comparativamente, o Brasil cresceu $106 \%$ no período de 1995 a 2010 , com crescimento médio anual em 15 anos de 4,9\%. Vale ainda observar que as menores taxas de crescimento do VA foram observadas para o Japão, Alemanha e EUA, não ultrapassando a casa dos $30 \%$ em todo período analisado.

Gráfico 3 - Valor Adicionado na Indústria Manufatureira, Países Selecionados, em US\$ milhões, em PPP, 1995-2010

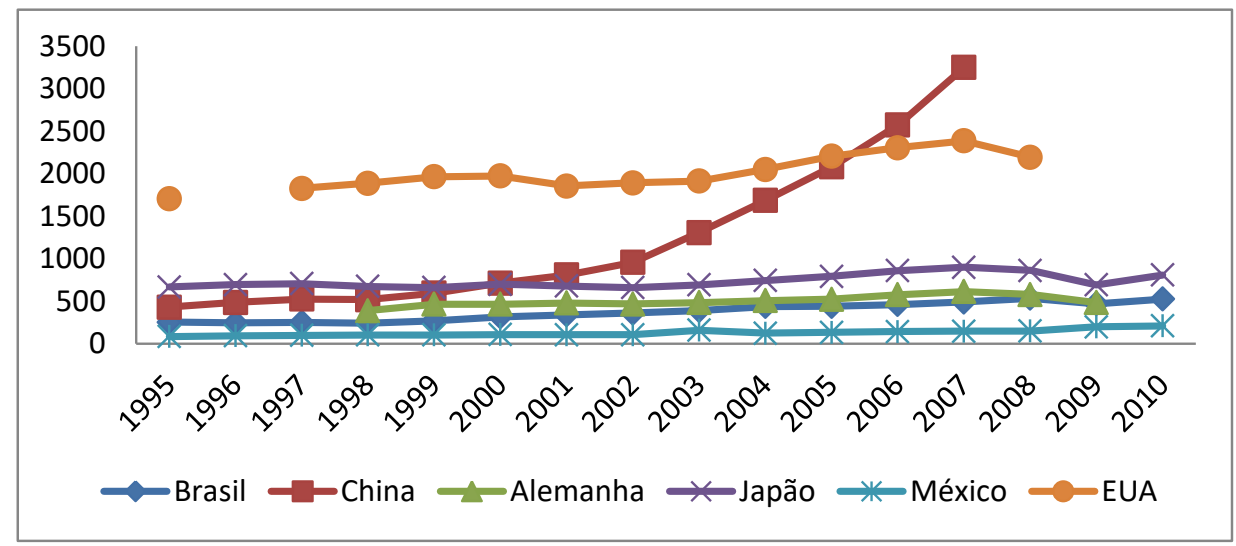

Fonte: Elaboração própria com base nos dados da UNIDO (2013)

Já as informações trazidas pelo gráfico 4 apresentam a distribuição do VA da indústria dos países por intensidade tecnológica, de acordo com a classificação da OCDE (1987) ${ }^{10}$. Sendo assim, demostram a evolução do VA por setores para os países selecionados.

Gráfico 4 - Participação do Valor Adicionado no Total da Indústria de Transformação, por Intensidade Tecnológica, Países Selecionados (1995-2010)

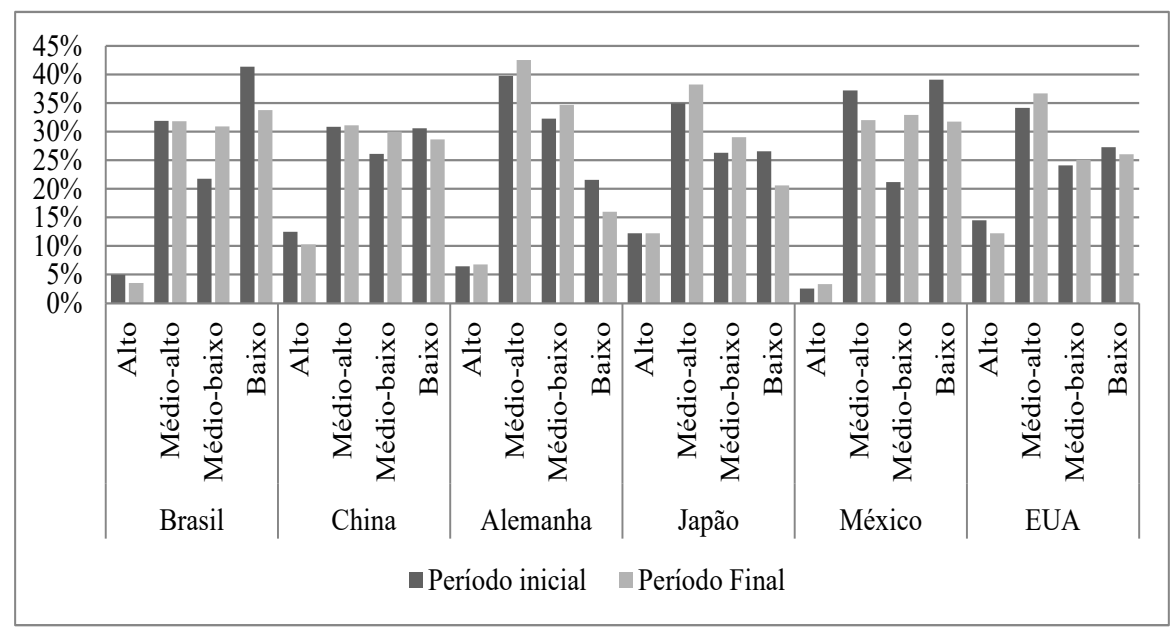

Nota: 1) os dados disponíveis compreendem entre o período de 1995 e 2010, entretanto, não se tem dados para todos os setores e todos os anos. Dessa forma, utilizaram-se os dados disponíveis para os países e os respectivos anos: Brasil (1996 e 2007), China (2003 e 2007), Alemanha (1999 e 2007), Japão (1995 e 2005), México (1995 e 2010) e EUA (1997e 2008); 2) classificação dos setores ISIC rev.3 a 2 dígitos de acordo com a OCDE.

Fonte: Elaboração própria com base nos dados da UNIDO (2013)

\footnotetext{
${ }_{9}^{9}$ Valores calculados em paridade do poder de compra em dólares estadunidenses.

${ }^{10}$ Dada simplicidade do nível de desagregação em que os dados disponíveis foram reportados, optou-se por utilizar a classificação tradicional da OCDE em setores de Alta (30 - Máquinas para escritório, contabilidade e informática; 32 - Equipamentos de comunicação, Rádio e TV; 33 - Instrumentos médicos, de precisão e ópticos), Média-Alta (24 - Produtos químicos; 29 - Máquinas e Equipamentos; 31 - Máquinas e Equipamentos Elétricos; 34 - Veículos motores, reboques; 35 - Outros equipamentos de transporte), Média-Baixa (23 - Coque, produtos petrolíferos refinados, combustível nuclear; 25 - Borracha; 26 - Produtos minerais não metálicos; 27 - Metalurgia; 28 - Produtos de Metal) e Baixa (15 - Alimentos e bebidas; 16 - Tabaco; 17 - Têxtil; 18 - Vestuário; 19 - Calçados e Couros; 20 - Produtos de Madeira; 21 - Papel e produtos de papel; 22 - Impressão; 36 - Móveis; 37 - Reciclagem) tecnologia.
} 
Observou-se que os setores brasileiros passaram por transformações na composição do VA, visto que aqueles de alta e de baixa tecnologia perderam participação para os setores de média-baixa tecnologia e com nível estável para os setores de média-alta tecnologia no período de 1996 a 2007. No ano de 2007, o setor de alta intensidade apresentou baixa participação $(3,51 \%)$, além de revelar queda na participação no período. O setor de baixa intensidade tecnológica obteve uma participação de $33,75 \%$ com uma queda de 7,6 pp no período. O grupo de setores de média-alta intensidade tecnológica foi o segundo a apresentar maior participação com $31,84 \%$ do total da manufatura, sendo que apresentou uma queda de $0,1 \mathrm{pp}$ no período. O conjunto de setores de média-baixa intensidade foi o único a apresentar variação positiva no período analisado, com alta de 9,2 pp e participação de 30,9\% em 2007. Entretanto, os setores de média-baixa e baixa intensidade tecnológica representavam juntos $64,65 \%$ do total do VA das manufaturas brasileiras no ano de 2007. Dessa forma, o país caracteriza-se por concentrar a produção em setores que necessitam de baixa tecnologia para produção.

A China apresentou crescimento na participação nos setores de média-baixa tecnologia e nível estável no setor de média-alta em torno de 31\%. Entretanto, a participação do VA nos setores de alta tecnologia, apesar de sofrer queda de 2,2 pp no período entre 2003 e 2007, apresentou uma estrutura próxima a países desenvolvidos como Japão e EUA, sendo que no final do período a participação foi de 10,26\%. O aumento da estrutura produtiva de alta intensidade tecnológica na China (medida pelo VA) está associado ao processo de constituição de redes globais de produção, a qual recebe as etapas estritamente produtivas nesse processo. Por outro lado, a participação do VA nos setores de alta e média-alta intensidade tecnológica de manufaturados chineses somaram $41,38 \%$ do total em 2007, valores acima da média para países em desenvolvimento. Quando comparado os mesmos setores para os EUA, esses representavam $48,9 \%$ do total.

Dessa forma, constatou-se por esse indicador que a China tem buscado estruturar sua indústria em direção a setores com maior conteúdo tecnológico. O país vem recebendo etapas produtivas, principalmente de países industrializados, que não estão somente concentrados em setores tradicionais, como calçados, alimentos e bebidas, mas constituem-se por produzir também máquinas e equipamentos de maior valor agregado.

Finalizando o grupo de países em desenvolvimento, observou-se que o México apresentou crescimento na participação do VA em setores de média-baixa tecnologia, com aumento de 11,8 pp no período de 1995 a 2010. Similarmente ao Brasil, a indústria manufatureira mexicana concentra-se a produção em setores de média-baixa e baixa intensidade tecnológica, que juntos somaram $64,64 \%$ do total de manufaturados ${ }^{11}$.

Por outro lado, a Alemanha apresentou variação percentual positiva em todos os segmentos, com exceção dos setores de baixa intensidade tecnológica. Os setores de alta e média-alta intensidade tecnológica representavam juntos $49,3 \%$ do total do VA da manufatura, sendo que $42,51 \%$ eram concentrado em setores de média-alta intensidade tecnológica. Esses setores representam a produção de produtos químicos e de máquinas e equipamentos elétricos, que tradicionalmente são produzidos por esse país e que ainda parece ter sobremaneira importância entre as manufaturas alemãs.

O Japão concentrava a produção em setores de média-alta tecnologia, juntamente com Alemanha e EUA. Esses países assemelham-se por apresentar variações percentuais positivas e significativas do VA nos setores de média (alta e baixa) intensidade tecnológica. Adicionalmente, esses países apresentaram queda significativa dos setores de baixa intensidade e em específico, os EUA, revelou queda nos setores de alta intensidade tecnológica.

O crescimento da participação do VA para as manufaturas japonesas de média-alta tecnologia foi de 3,3 pp no período de 1995 a 2005, com parcela de 38,21\% em 2005. Observado os mesmos setores na Alemanha, o crescimento foi de 2,8 pp e nos EUA revelaram uma alta de $2,5 \mathrm{pp}$. Ainda, cumpre ressaltar que o indicador apresentado sugere que os EUA apresentaram queda em setores típicos do paradigma da microeletrônica (setores de alta intensidade tecnológica ou intensivos em conhecimento).

Para um maior posicionamento da indústria brasileira frente à fronteira tecnológica, pela ótica do VA, analisou-se os dez setores com maior participação do VA na indústria de transformação e quanto cada setor contribuiu para o crescimento da indústria total ${ }^{12}$. Além disso, apresenta-se a distância dos setores brasileiros em relação a fronteira tecnológica mensurado a partir do gap de produtividade ${ }^{13}$ (Tabela 1).

Entre 1996 e 2007, o VA da manufatura brasileira cresceu 99,3\%, sendo que a maior contribuição para esse crescimento foi observado para as atividades de coque e refino de petróleo $(18,8 \%)$, alimentos e bebidas $(15,3 \%)$, metalurgia $(11,3 \%)$ e veículos motores, reboques $(10,4 \%)$. Entre os dez setores, três podem ser considerados sucesso

\footnotetext{
${ }^{11}$ Cumpre ainda ressaltar que os três países em desenvolvimento coincidem por apresentar variação percentual positiva e significativa nos setores de média-baixa tecnologia (México - 11,8\%; Brasil - 9,2\%; China - 3,8\%).

${ }_{12}$ A taxa de contribuição para o crescimento pode ser encontrada a partir do produto entre a participação de uma determinada variável (neste caso o VA) no período inicial e o crescimento da variável no período final.

${ }^{13}$ O gap de produtividade é calculado a partir do diferencial entre o país analisado e os EUA (considerada a fronteira tecnológica por representar a maior produtividade no período). A produtividade, por sua vez, é mensurada por meio da razão entre o pessoal ocupado e o valor adicionado nas atividades da indústria de transformação. O valor adicionado (e não o valor bruto da produção) é utilizado para esse cálculo, pois são desconsiderados os insumos e componentes importados. Dessa forma, contornam-se as limitações de um suposto efeito maquila.
} 
na realização de catching up, uma vez que diminuíram o hiato de produtividade em relação à fronteira. Por outro lado, o setor de "coque e refino de petróleo" é um caso a parte, sendo sucesso de catching up, uma vez que possuía produtividade superior aos $\mathrm{EUA}^{14}$, contudo o setor tem ampliado a lacuna de produtividade em relação à fronteira no período entre 1998 e 2007. Esses três setores somavam 23,6\% do total do VA da indústria manufatureira, já os setores que fizeram falling behind, representavam 55,5\% do total do VA em 2007. Dos 22 setores analisados ${ }^{15}$, somente esses setores brasileiros no período entre 1998 e 2007 realizaram processo de catching up, o que está aquém quando em comparação com a China, que fez catching up em 20 setores, no período de 2004 e 2007.

Tabela 1 - 10 atividades com maiores participações do VA no total da indústria de transformação brasileira, por intensidade tecnológica, distância em relação a fronteira, taxa de contribuição, 1996-2007

\begin{tabular}{|c|c|c|c|c|c|}
\hline ISIC & Descrição do Setor & $\begin{array}{l}\text { Intensidade } \\
\text { Tecnológica }\end{array}$ & $\begin{array}{c}\text { Distância em relação } \\
\text { a fronteira }\end{array}$ & $\begin{array}{c}\text { Taxa de } \\
\text { Contribuição }\end{array}$ & $\begin{array}{l}\text { Participação } \\
\text { (2007) }\end{array}$ \\
\hline 15 & Alimentos e bebidas & baixa & Falling behind & $15,3 \%$ & $17,5 \%$ \\
\hline 23 & Coque, produtos petroliferos refinados, combustivel nuclear & média-baixa & Forging ahead & $18,8 \%$ & $11,5 \%$ \\
\hline 24 & Produtos químicos & média-alta & Falling behind & $9,5 \%$ & $11,2 \%$ \\
\hline 34 & Veículos motores, reboques & média-alta & Catching up & $10,4 \%$ & $9,2 \%$ \\
\hline 27 & Metalurgia & média-baixa & Catching up & $11,3 \%$ & $8,4 \%$ \\
\hline 29 & Máquinas e Equipamentos & média-alta & Falling behind & $6,2 \%$ & $6,7 \%$ \\
\hline 28 & Produtos de Metal & média-baixa & Falling behind & $4,2 \%$ & $4,1 \%$ \\
\hline 21 & Papel e produtos de papel & baixa & Catching up & $3,4 \%$ & $3,6 \%$ \\
\hline 25 & Borracha & média-baixa & Falling behind & $2,9 \%$ & $3,6 \%$ \\
\hline \multirow[t]{2}{*}{26} & Produtos minerais não metálicos & média-baixa & Falling behind & $3,0 \%$ & $3,3 \%$ \\
\hline & & & & $100,0 \%$ & $100,0 \%$ \\
\hline
\end{tabular}

Nota: 1) Dados para o VA compreendem o período entre 1996-2007; 2) A distância em relação a fronteira foi calculada a partir do diferencial do hiato de produtividade entre o Brasil e os EUA, no período de 1998 a 2007 Fonte: Elaboração própria com base nos dados da UNIDO (2013)

No tocante às mudanças estruturais pela ótica do emprego industrial, o gráfico 5 mostra a distribuição do emprego da indústria de transformação por intensidade tecnológica dos países selecionados. O Brasil concentrava a maior parte dos empregados em setores de baixa intensidade tecnológica $(53,91 \%)$ no ano de 2007 , apesar de observar diminuição da participação de 1,4 pp nesses setores e também nos de alta tecnologia com queda de 0,05 pp, no período entre 1996 e 2007. Os setores de média-baixa tecnologia apresentaram-se estáveis e os setores de média-alta apresentaram crescimento da variação no período em um ponto percentual.

Gráfico 5 - Participação do Emprego no Total da Indústria de Transformação, por Intensidade Tecnológica, Países Selecionados (1995-2010)

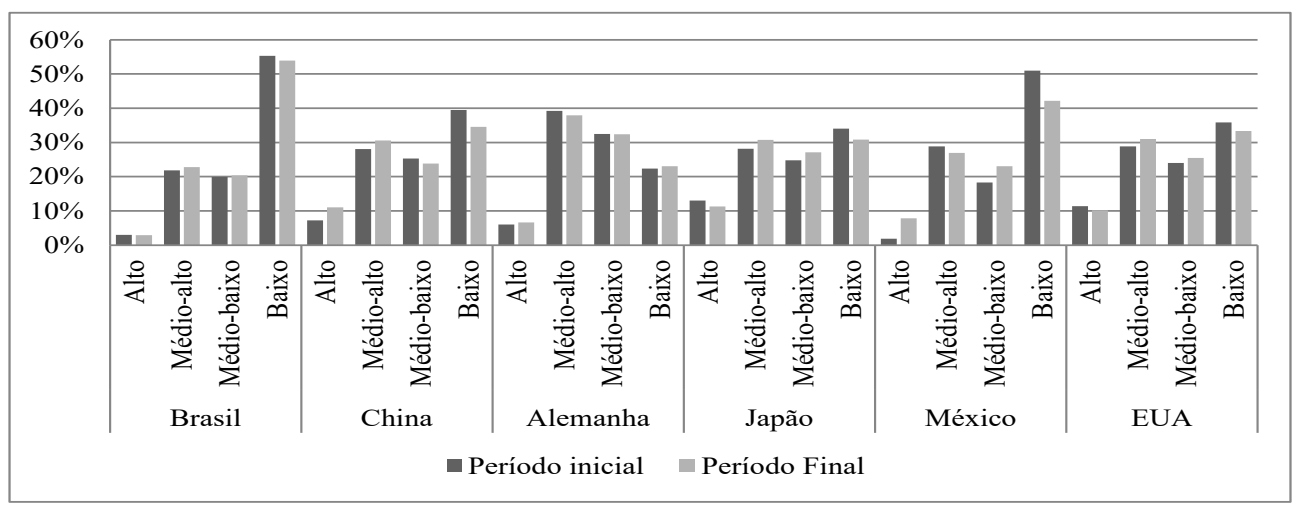

Nota: 1) os dados disponíveis compreendem entre o período de 1995 e 2010, entretanto, não há dados para todos os setores e todos os anos. Dessa forma, utilizaram-se os dados disponíveis para os países e os respectivos anos: Brasil (1996 e 2007), China (2003 e 2010), Alemanha (1995 e 2007), Japão (1995 e 2005), México (1995 e 2010) e EUA (1997 e 2008); 2) classificação dos setores ISIC ver.3 a 2 dígitos de acordo com a OCDE.

Fonte: Elaboração própria com base nos dados da UNIDO (2013)

\footnotetext{
${ }^{14} \mathrm{O}$ setor pode ser classificado como forging ahead, de acordo com Abramovitz (1986), uma vez que a produtividade é superior do que a fronteira internacional.

${ }^{15} \mathrm{O}$ setor reciclagem não possuía dados para os EUA, que impossibilitou avaliar o processo de catching up para esse setor.
} 
O processo de mudança estrutural da China foi constatado também pela mudança da estrutura do emprego de setores de média-baixa e baixa tecnologia para os de alta e média-alta tecnologia, com variação de crescimento nesses setores de 3,79 pp e 2,54 pp respectivamente ${ }^{16}$. Entretanto, o emprego na indústria chinesa tem maior concentração nos setores de baixa intensidade tecnológica com participação de $34,57 \%$ e setores de média-alta $(30,58 \%)$ intensidade tecnológica.

Por outro lado, a mudança no emprego industrial mexicano apresentou queda da participação de setores de média-alta e baixa tecnologia para o aumento dos setores de alta e média-baixa tecnologia. Destacam-se os setores de alta tecnologia que revelou uma variação em 6 pp no período de 1995 e 2010. Nesse sentido, dentre os países em desenvolvimento, somente o Brasil não apresentou crescimento na participação do emprego de alta tecnologia.

Para os países desenvolvidos, a Alemanha apresentou baixo crescimento da participação nos setores de alta e baixa tecnologia, ao passo que esta participação apresenta queda nos setores de média-alta e mantem estável nos setores de média-baixa. Observou-se que o padrão de distribuição no emprego industrial alemão não sofreu modificações significativas. Cumpre destacar que as maiores concentrações eram nos setores de média-alta $(37,88 \%)$ e média-baixa $(32,42 \%)$ tecnologia no ano de 2007.

Os processos de mudança no emprego japonês e estadunidense apresentaram aumentos na participação em setores de média (alta e baixa) tecnologia e decrescimento nos setores de alta e baixa tecnologia. Similarmente ao observado pela ótica do VA. As maiores concentrações de empregados nos dois países foram em setores de baixa intensidade tecnológica.

Ainda pela ótica do emprego, as dez maiores participações do emprego nas atividades industriais brasileiras são apresentadas na tabela 2. As duas maiores participações são observadas para setores manufaturados tradicionais, como o de alimentos e bebidas e vestuário. A atividade de "máquinas e equipamentos" da indústria eletrônica, típicos do paradigma vigente aparece entres as maiores participações, representando $7,2 \%$ do total de empregados.

Tabela 2 - 10 atividades com maiores participações do emprego no total da indústria de transformação brasileira, por intensidade tecnológica, distância em relação à fronteira, taxa de contribuição, 1996-2007

\begin{tabular}{|c|c|c|c|c|c|}
\hline ISIC & Descrição do Setor & $\begin{array}{l}\text { Intensidade } \\
\text { Tecnológica }\end{array}$ & $\begin{array}{c}\text { Distância em relação } \\
\text { a fronteira }\end{array}$ & $\begin{array}{c}\text { Taxa de } \\
\text { Contribuição }\end{array}$ & $\begin{array}{l}\text { Participação } \\
\quad \text { (2007) }\end{array}$ \\
\hline 15 & Alimentos e bebidas & baixa & Falling behind & $25,1 \%$ & $21,8 \%$ \\
\hline 18 & Vestuário & baixa & Falling behind & $8,5 \%$ & $7,9 \%$ \\
\hline 29 & Máquinas e Equipamentos & média-alta & Falling behind & $8,6 \%$ & $7,2 \%$ \\
\hline 28 & Produtos de Metal & média-baixa & Falling behind & $8,2 \%$ & $6,4 \%$ \\
\hline 34 & Veículos motores, reboques & média-alta & Catching up & $6,2 \%$ & $5,9 \%$ \\
\hline 19 & Calçados e couros & baixa & Falling behind & $6,4 \%$ & $5,8 \%$ \\
\hline 24 & Produtos químicos & média-alta & Falling behind & $4,0 \%$ & $5,2 \%$ \\
\hline 25 & Borracha & média-baixa & Falling behind & $5,8 \%$ & $5,2 \%$ \\
\hline 26 & Produtos minerais não metálicos & média-baixa & Falling behind & $4,6 \%$ & $5,0 \%$ \\
\hline \multirow[t]{2}{*}{17} & Textil & baixa & Falling behind & $1,9 \%$ & $4,7 \%$ \\
\hline & & & & $100,0 \%$ & $100,0 \%$ \\
\hline
\end{tabular}

Nota: 1) Dados para o emprego compreende o período entre 1996-2007; 2) A distância em relação a fronteira foi calculada a partir do diferencial do hiato de produtividade entre o Brasil e os EUA, no período de 1997 e 2007 Fonte: Elaboração própria com base nos dados da UNIDO (2013)

O crescimento no emprego total da manufatura brasileira foi de $41,9 \%$ entre 1996 e 2007, segundo dados da UNIDO. O setor que mais contribuiu para esse crescimento foi o de alimentos e bebidas, com uma parcela de $25,1 \%$ do crescimento do emprego no Brasil, sendo esse setor responsável por empregar $21,8 \%$ do total de empregados na indústria brasileira no ano de 2007. Dentre os dez setores que mais empregam no Brasil, nove tem levado o país a um processo de falling behind, representando $69,2 \%$ do total de empregados. Em outras palavras, o emprego na indústria brasileira vem aumentando em setores que tem diminuído a produtividade em relação à fronteira internacional.

Dessa forma, pela ótica do emprego, o processo de mudança estrutural da indústria brasileira não tem proporcionado o país a ganhar posicionamento frente à fronteira internacional. Os setores que mais empregam no Brasil tem ampliado a lacuna de produtividade e levado o país a um processo de falling behing. Quando observado setores ligados ao paradigma vigente, somente um setor aparece entre os que mais empregam no país. Assim sendo, parece

\footnotetext{
${ }^{16}$ Observou-se que a China foi o país a apresentar maior volume de empregados na indústria dentre todos os países da amostra, de acordo com os dados da UNIDO (2013). A indústria de transformação chinesa apresentou um crescimento de $63,82 \%$ no total de empregados entre os anos de 2003 e 2010 em números absolutos.
} 
que o Brasil não tem fomentado políticas para a penetração de TICs na base produtiva nacional, tanto pela ótica do emprego quanto pela do VA.

Segundo Arend e Fonseca (2012), entre o período de 1980 e 2005 "a economia brasileira ingressou em um processo de falling behind, o qual foi fortemente influenciado pela dinâmica tecnológica e financeira da fase inicial do quinto paradigma tecnoeconômico" ${ }^{17}$. Assim, o atraso tecnológico é um dos fatores que tem evidenciado o falling behind da trajetória de desenvolvimento capitalista brasileiro (AREND e FONSECA, 2012). Dessa maneira, os dados mais recentes confirmam a tese desses autores.

De forma auxiliar, a tabela 3 posiciona a indústria brasileira de maneira agregada e traz informações que auxiliam a compreensão do posicionamento por grupo de setores tecnológicos frente à fronteira internacional, além de revelar o quanto o processo de mudança estrutural (por meio do incremento do emprego, VA e exportação) dos setores tem contribuído para o crescimento total da indústria manufatureira.

Nesse sentido, constatou-se que os setores de baixa intensidade tecnológica, além de apresentarem maior contribuição para o aumento do emprego no país, com uma taxa de 53,52\% entre os anos de 1996 e 2007, são os mesmos que exerceram maior contribuição para o crescimento das exportações brasileiras, com uma contribuição de $44,79 \%$ no período entre 1995 a 2010. Cumpre ressaltar que os setores de baixa tecnologia possuem menor valor agregado e não contribuem de maneira significativa para o crescimento do VA da indústria total. Nesse sentido, o processo de mudança estrutural desses setores tem levado a um processo de falling behing da indústria manufatureira brasileira.

Tabela 3 - Distância dos setores por intensidade tecnológica em relação à fronteira, Taxas de contribuição do Emprego, VA e Exportações, 1996-2007

\begin{tabular}{llccc}
\hline \multirow{2}{*}{ Setor OCDE } & \multicolumn{1}{c}{$\begin{array}{c}\text { Distância em } \\
\text { Relação aos EUA }\end{array}$} & \multicolumn{3}{c}{ Taxas de Contribuição } \\
\cline { 3 - 5 } & Ealling behind & $2,98 \%$ & $2,10 \%$ & Exportações \\
\hline Alta & Falling behind & $24,01 \%$ & $30,89 \%$ & $31,17 \%$ \\
Média-alta & Catching up & $19,49 \%$ & $40,56 \%$ & $21,06 \%$ \\
Média-baixa & Falling behind & $53,52 \%$ & $26,45 \%$ & $44,79 \%$ \\
Baixa & Falling behind & $\mathbf{1 0 0 , 0 0 \%}$ & $\mathbf{1 0 0 , 0 0 \%}$ & $\mathbf{1 0 0 , 0 0 \%}$ \\
\hline Total da Manufatura
\end{tabular}

Fonte: Elaboração própria com base nos dados da UNIDO (2013).

Nota: 1) Dados da UNIDO e seus respectivos períodos: para emprego (1996-2007), VA em PPP (19962007) e Exportações (1995-2010); 2) Dados para exportações são reportados a quatro dígitos da classificação ISIC rev. 3 e agregados a 2 dígitos; 3) A distância em relação a fronteira foi calculada a partir do diferencial do hiato de produtividade entre o Brasil e os EUA, no período de 1997 e 2007.

Por outro lado, os setores de média-baixa intensidade tecnológica brasileiros são um caso de sucesso de catching up da indústria nacional. Esses são impulsionados pela participação de dois setores, "coque e refino de petróleo" e "metalurgia", sendo o primeiro responsável pelo maior aumento de produtividade dos setores de média-baixa tecnologia, como já analisado anteriormente.

Outros dados importantes a se observar na dimensão tecnológica são os dispêndios em P\&D. Cumpre destacar que a $P \& D$ exerce uma função importante em todo o processo de produção de conhecimento de modo a garantir que as empresas conquistem a produção de novos conhecimentos e produtos, além de ampliar a absorção de conhecimento e aprendizado (COHEN e LEVINTHAL, 1989) e de certa forma são responsáveis pelos incrementos de produtividade nas atividades industriais. Dessa maneira, a tabela 4 apresenta as estrutura dos gastos de P\&D dos países selecionados.

Todos os países da amostra apresentaram concentração das participações dos dispêndios em P\&D em setores de média-alta tecnologia, com exceção dos EUA. Observa-se que o padrão de P\&D em países desenvolvidos está direcionado a setores com maior conteúdo tecnológico, ao passo que os países em desenvolvimento o padrão se concentra em setores de média-baixa e baixa intensidade tecnológica.

No que diz respeito a estrutura de P\&D chinesa, observa-se que no período entre 2008 e 2014 ampliaram em 7,76 pp a participação em setores de alta intensidade tecnológica. Países como México, Alemanha e Japão também apresentaram tendência de alta nesses setores, contudo em períodos distintos. Na contramão mundial, o Brasil apresentou queda na participação desses setores.

17 O quinto paradigma técnico-econômico é o baseado na microeletrônica (AREND e FONSECA, 2012), ou quinta revolução tecnológica, associada às tecnologias da informação e comunicação (PEREZ, 2010). 
Tabela 4 - Estrutura dos dispêndios de P\&D da indústria manufatureira, por intensidade tecnológica, países selecionados, 1995-2014

\begin{tabular}{|c|c|c|c|c|c|c|}
\hline \multirow[b]{2}{*}{ Grupo de Setores OCDE } & \multicolumn{2}{|c|}{ Alemanha } & \multicolumn{2}{|c|}{ Japão } & \multicolumn{2}{|c|}{ EUA } \\
\hline & 1995 & 2007 & 1995 & 2014 & 1998 & 2 \\
\hline Alta & $34,54 \%$ & $31,42 \%$ & $36,93 \%$ & $37,06 \%$ & $61,79 \%$ & $74,25 \%$ \\
\hline Média-alta & $57,08 \%$ & $60,12 \%$ & $43,98 \%$ & $50,43 \%$ & $28,72 \%$ & $16,68 \%$ \\
\hline Média-baixa & $5,74 \%$ & $5,97 \%$ & $13,11 \%$ & $8,09 \%$ & $7,10 \%$ & $3,65 \%$ \\
\hline Baixa & $2,64 \%$ & $2,48 \%$ & $5,98 \%$ & $4,41 \%$ & $2,38 \%$ & $5,43 \%$ \\
\hline Total da Manufatura & $100,00 \%$ & $100,00 \%$ & $100,00 \%$ & $100,00 \%$ & $100,00 \%$ & $100,00 \%$ \\
\hline \multicolumn{7}{|l|}{ Países em Desenvolviment } \\
\hline & \multicolumn{2}{|c|}{ México } & \multicolumn{2}{|c|}{ China } & \multicolumn{2}{|c|}{ Brasil } \\
\hline Grupo de Setores OCDE & 1995 & 2009 & 2008 & 2014 & 2000 & 2014 \\
\hline Alta & $13,23 \%$ & $13,11 \%$ & $26,77 \%$ & $21,98 \%$ & $10,86 \%$ & $9,08 \%$ \\
\hline Média-alta & $46,36 \%$ & $50,71 \%$ & $38,62 \%$ & $46,38 \%$ & $40,16 \%$ & $37,76 \%$ \\
\hline Média-baixa & $9,35 \%$ & $17,24 \%$ & $24,50 \%$ & $20,32 \%$ & $24,43 \%$ & $24,84 \%$ \\
\hline Baixa & $31,06 \%$ & $18,95 \%$ & $10,12 \%$ & $11,32 \%$ & $24,55 \%$ & $28,32 \%$ \\
\hline Total da Manufatura & $100,00 \%$ & $100,00 \%$ & $100,00 \%$ & $100,00 \%$ & $100,00 \%$ & $100,00 \%$ \\
\hline
\end{tabular}

Fonte: Elaboração própria com base nos dados da PINTEC (IBGE) e OCDE

Especificamente, no Brasil, os gastos de P\&D concentram-se em setores intensivos em escala e baseados em recursos naturais. Esse último grupo de setores aumentou sua participação no total dos gastos em P\&D em 11 pp no período entre 2000 e 2014, ao passo que o primeiro decresceu em 9 pontos percentuais (Gráfico 6).

Nesse sentido, observa-se uma tendência de queda da estrutura tecnológica brasileira em setores com maior intensidade tecnológica em detrimento da especialização produtiva (em consequência disso, também da estrutura de P\&D) em setores baseados em recursos naturais, com menor intensidade tecnológica. Em 2014, os setores intensivos em escala detinham 39\% do total de gastos em P\&D da indústria de transformação, segundo dados da PINTEC, o que contrasta com os $48 \%$ no ano de 2000 (Gráfico 6). Esses setores podem ser também classificados como média-alta intensidade tecnológica de acordo com a OCDE.

Os setores baseados em recursos naturais são de extrema importância para a estrutura produtiva brasileira. Observou-se a partir dos indicadores de emprego e VA que há uma especialização relativa da estrutura produtiva brasileira na direção de atividades baseadas em baixo teor tecnológico, especificamente atividades baseadas em recursos naturais. Constatou que a estrutura industrial brasileira apresentava mais da metade dos empregos industriais concentrados em setores de baixa tecnologia. Por conseguinte, o crescimento dos gastos destinados à ciência e a tecnologia no país seguem na mesma direção da estrutura produtiva.

Gráfico 6 - Distribuição dos gastos em P\&D na indústria manufatureira, Brasil, por determinante de competitividade, $2000-2014$

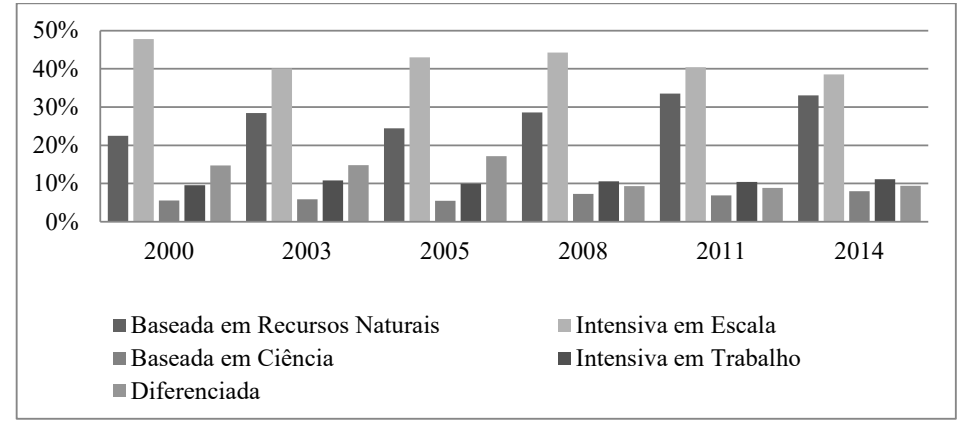

Fonte: Elaboração própria com base nos dados da PINTEC-IBGE

Assim sendo, os resultados sugerem que os setores intensivos em recursos naturais no Brasil podem ser mais intensivos em tecnologia do que postula a classificação tradicional da OCDE. Furtado e Carvalho (2005, p. 78) encontraram evidências, pela ótica dos recursos humanos dedicados a $\mathrm{P} \& \mathrm{D}$, que "o padrão de esforço da indústria brasileira não se concentra nos setores de alta intensidade tecnológica" quando comparado a estrutura dos EUA.

Nesse sentido, a tabela 5 apresenta o pessoal ocupado em atividades de P\&D em relação ao total ocupado da indústria no mesmo ano. Esse indicador revela a intensidade tecnológica dos países na qual os setores são agrupados de acordo com a intensidade tecnológica. 
Tabela 5 - Intensidade de PO em P\&D da indústria manufatureira, por intensidade tecnológica, países selecionados, 1995-2010

\begin{tabular}{|c|c|c|c|c|c|c|}
\hline \multirow[b]{2}{*}{ Grupo de Setores OCDE } & \multicolumn{2}{|c|}{ Alemanha } & \multicolumn{2}{|c|}{ Japão } & \multicolumn{2}{|c|}{ EUA } \\
\hline & 1995 & 2008 & 1995 & 2010 & - & - \\
\hline Alta & $19,63 \%$ & $15,76 \%$ & $14,86 \%$ & $26,80 \%$ & nd & nd \\
\hline Média-alta & $5,12 \%$ & $5,56 \%$ & $8,00 \%$ & $9,98 \%$ & nd & nd \\
\hline Média-baixa & $1,08 \%$ & $1,18 \%$ & $3,11 \%$ & $3,09 \%$ & nd & nd \\
\hline Baixa & $0,53 \%$ & $0,55 \%$ & $1,17 \%$ & $1,54 \%$ & nd & nd \\
\hline $\begin{array}{l}\text { Total da Manufatura } \\
\end{array}$ & $3,98 \%$ & $4,05 \%$ & $5,43 \%$ & $7,41 \%$ & nd & nd \\
\hline \multicolumn{7}{|l|}{ Países em Desenvolvimento } \\
\hline & \multicolumn{2}{|c|}{ México } & \multicolumn{2}{|c|}{ China } & \multicolumn{2}{|c|}{ Brasil } \\
\hline Grupo de Setores OCDE & 1995 & 2010 & 2008 & 2010 & 2006 & 2010 \\
\hline Alta & $0,29 \%$ & $1,70 \%$ & $3,70 \%$ & $4,74 \%$ & $3,42 \%$ & $9,67 \%$ \\
\hline Média-alta & $0,11 \%$ & $0,24 \%$ & $1,68 \%$ & $2,15 \%$ & $2,36 \%$ & $2,25 \%$ \\
\hline Média-baixa & $0,05 \%$ & $0,11 \%$ & $0,93 \%$ & $1,23 \%$ & $1,07 \%$ & $1,64 \%$ \\
\hline Baixa & $0,09 \%$ & $0,07 \%$ & $0,38 \%$ & $0,53 \%$ & $0,69 \%$ & $0,85 \%$ \\
\hline Total da Manufatura & $0,09 \%$ & $0,16 \%$ & $1,23 \%$ & $1,66 \%$ & $1,30 \%$ & $1,57 \%$ \\
\hline
\end{tabular}

Nota: nd - dados não disponíveis na base da OCDE

Fonte: Elaboração própria com base nos dados da RAIS (MTE), UNIDO (2013) e OCDE

A estrutura produtiva de países industrializados é especializada em setores de alta e média-alta intensidade tecnológica e, consequentemente, a estrutura de P\&D e o esforço tecnológico (mensurado pela intensidade de PO em P\&D) concentram-se nesses setores. Furtado e Carvalho (2005) lembram que as barreiras à entrada de setores de alta e média-alta intensidade tecnológica de países industrializados são elevadas e as empresas desses países necessitam realizar esforços tecnológicos substanciais para reforçar a constituição de seu posicionamento competitivo no mercado global.

Observa-se que países desenvolvidos possuem uma maior intensidade de pessoal ocupado em P\&D setores de alta e média-alta intensidade, ao passo que os países em desenvolvimento possuem baixa intensidade, quando comparado com os primeiros. O esforços tecnológicos da manufatura total na China, em 2010 , representava cerca de $1,66 \%$ do pessoal ocupado em P\&D no total de empregados na indústria manufatureira, quando comparado ao Brasil essa marca representou no mesmo ano cerca de $1,57 \%$. Entretanto, vale lembrar que em números absolutos a China empregou mais mão de obra em atividades tecnológicas do que os países desenvolvidos e aqueles em desenvolvimento.

Destaca-se que os setores de alta intensidade tecnológica no Brasil, obedecendo à classificação da OCDE (setores de Máquinas para escritório, contabilidade e informática; Equipamentos de comunicação, Rádio e TV; Instrumentos médicos, de precisão e ópticos), obtiveram um resultado de esforço tecnológico acima da média dos países em desenvolvimento. Ressalta-se, o maior esforço tecnológico empregado em atividades de alta tecnologia no Brasil em proporção do total empregado no mesmo setor. Entretanto, ainda está aquém dos setores de alta tecnologia de países desenvolvidos. Observa-se que esse resultado pode estar ocasionando uma ilusão estatística, uma vez que a estrutura de PO em atividades de P\&D, em 2010, estava concentrada em setores de média-alta tecnologia (36\%) seguida por setores de baixa (28\%) e média-baixa tecnologia (22\%). Nesse sentido, o menor número de PO em P\&D estavam empregados em setores de alta tecnologia no Brasil, cerca de 16,4 mil em termos absolutos o que representava $14 \%$ da estrutura brasileira.

Ainda, de acordo com dados da OCDE, a China empregou 2,8 milhões de pessoas em atividades de P\&D na indústria manufatureira em 2014 e o México aproximadamente 14 mil em 2013. De acordo com dados da RAIS, o Brasil empregou, em 2014, cerca de 143 mil pessoas em atividades tecnológicas. Alemanha empregava em 2008 cerca de 332 mil e o Japão 611 mil pessoas em atividade de P\&D. Esses resultados sugerem, ainda, um forte deslocamento, não somente das etapas produtivas, mas também das atividades de P\&D de grandes empresas e seus laboratórios para a China.

\section{Conclusões}

Esse trabalho propôs investigar os impactos na estrutura produtiva brasileira e de países selecionados a partir das transformações na dimensão tecnológica. Levou-se em consideração as transformações na natureza competitiva da indústria global associada ao paradigma técnico-econômico da microeletrônica.

Observou-se que a China passou a se industrializar ao receber etapas do processo produtivo manufatureiro mundial, fragmentado em redes globais de produção. Por outro lado, países industrializados como Alemanha, Japão e EUA passaram por um processo de desindustrialização no período recente, considerado pela literatura especializada como normal. No mesmo sentido, Brasil e México, passam pelo fenômeno da desindustrialização, entretanto, os impactos competitivos são considerados um processo de desindustrialização precoce, uma vez que não atingiram um grau de desenvolvimento considerável. 
As evidências de desindustrialização consideradas por esse estudo foram as perdas sistemáticas no valor adicionado industrial no PIB e a perda do emprego industrial no total dos países analisados. Fatores como a globalização e medidas liberalizantes do sistema produtivo e financeiro têm levado as empresas a realocarem os recursos produtivos com base no modelo de gestão associado à maximização do valor acionário somado a uma reconfiguração da produção baseada na modularização da produção em nível global, cujas etapas estão dispersas pela periferia capitalista e concentradas nas regiões sul e sudeste asiática. Destaca-se a China, em períodos mais regentes, como o grande país receptor dessas etapas produtivas fragmentadas tornando-se a workshop of the world, que fez com que o país tivesse um maior posicionamento competitivo no mercado global, além de proporcionar fortemente o crescimento econômico e tecnológico do país.

Esse trabalho apresentou e defende duas hipóteses que estão relacionadas e dependentes sobre o processo de mudança estrutural dos países. Primeiro, a queda da participação do emprego está relacionada ao aumento de produtividade proporcionado pela propagação do novo paradigma tecnológico da microeletrônica e segundo, a queda do emprego é resultado de uma nova divisão internacional do trabalho. Ou seja, as transformações paradigmáticas se refletem nas modificações da estrutura produtiva dos países.

Dessa forma, a microeletrônica e as tecnologias da informação e comunicação podem ter proporcionado ganhos de produtividade na indústria manufatureira, fazendo com que o movimento da mão de obra seguisse no sentido do setor de serviços. Em adição, criou-se uma nova divisão internacional do trabalho, não somente impulsionada pelas transformações de natureza técnica, mas também de ordem financeira. As grandes empresas têm adotado estratégias que visam a maximização dos retornos dos acionistas e levam ao downsize das atividades estritamente produtivas em países desenvolvidos. Essas atividades estão geograficamente dispersas nas periferias capitalistas e ligadas em redes.

A partir desse cenário, a produtividade torna-se imprescindível para a análise das mudanças estruturais dos países. Os incrementos de produtividade são a principal chave para a competitividade dos países, além de permitir que esses se movimentem em direção à fronteira internacional. No caso brasileiro, observa-se um atraso tecnológico, principalmente em setores típicos do paradigma microeletrônico, além de se observar um aumento do gap de produtividade que tem levado a economia brasileira a um caminho de falling behind. O atraso tecnológico brasileiro é constatado pelo baixo esforço tecnológico mensurado a partir de atividades de P\&D, quando comparado a outros países selecionados.

Pela ótica do emprego, as atividades que mais empregam e contribuem para o crescimento da força de trabalho da indústria no Brasil ampliaram o gap de produtividade e levam a economia a um falling behing. Destacam-se os setores de "alimentos e bebidas" e "vestuário", os quais apresentaram maiores participações do emprego em 2007 e apresentam baixa intensidade tecnológica. Conclui-se que o processo de mudança estrutural da indústria brasileira não tem proporcionado o país a ganhar posicionamento frente à fronteira internacional. $O$ país não tem fomentado políticas para a penetração de TICs na base produtiva nacional, tanto pela ótica do emprego quanto pela do VA.

\section{Referências}

ABRAMOVITZ, M. Catching up, forging ahead, and falling behind. The Journal of Economic History, v. 46, n. 02, p. 385-406, 1986.

AREND, M. A industrialização do Brasil ante a nova divisão internacional do trabalho. Texto para Discussão, Instituto de Pesquisa Econômica Aplicada (IPEA), 2015.

AREND, M.; CEZAR, P.; FONSECA, D. 25 anos de catching up , 25 anos de falling behind. Revista de Economia Política, v. 32, n. 126, p. 33-54, 2012.

CARNEIRO, R. Desenvolvimento em crise: a economia brasileira no último quarto do século XX. Unesp, 2002.

CHANDLER, A. D. Scale and scope: The dynamics of industrial capitalism. Cambridge, Mass, 1990.

COHEN, W. M.; LEVINTHAL, D. A. Innovation and Learning: The Two Faces of R\&D. The Economic Journal, v. 99, n. 397, p. 569-596, set. 1989.

COUTINHO, L. A terceira revolução industrial e tecnológica: as grandes tendências de mudança. Economia e sociedade, v. 1, n. 8, p. 69-87, 1992.

CROTTY, J. "The effects of increased product market competition and changes in financial markets on the performance of Nonfinancial Corporations in the neoliberal era". PERI Working paper, n. 44, 2002. 
ERNST, D.; KIM, L. "Global production networks, knowledge diffusion, and local capability formation".

Research Policy, n. 31, p. 1417-1429, 2002.

EUROPEAN COMMISSION - EC. European Competitiveness Report: Towards Knowledge-driven Reindustrialisation. Commission Staff Working Document, 2013.

FURTADO, A. T.; CARVALHO, R. Q. Padrões de intensidade tecnológica da indústria brasileira: um estudo comparativo com os países centrais. São Paulo em Perspectiva, v. 19, n. 1, p. 70-84, 2005.

GEREFFI, G. Development Models and Industrial Upgrading in China and Mexico. European Sociological Review, v. 25, n. 1, p. 37-51, 2009.

GEREFFI, G. International trade and industrial upgrading in the apparel commodity chain. Journal of international economics, v. 48, n. 1, p. 37-70, 1999.

GEREFFI, G; HUMPHREY, J; STURGEON, T. The governance of global value chains. Review of international political economy, v. 12, n. 1, p. 78-104, 2005.

LAZONICK, W. From Innovation to Financialization: How Shareholder Value Ideology is Destroying the US Economy. 2011. Disponível em http://www.theairnet.org/files/research/lazonick/Lazonick\%20Innovation\%20 Financialization\%2020110616.pdf. Acesso em 29 nov. 2015

LAZONICK, W. The Chandlerian corporation and the theory of innovative enterprise. Industrial and Corporate Change, v. 19, n. 2, p. 317-349, 2010.

LAZONICK, W; O'SULLIVAN, M. Maximizing shareholder value: a new ideology for corporate governance. Economy and society, v. 29, n. 1, p. 13-35, 2000.

MOWERY, D.C.; ROSENBERG, N. Trajetórias da Inovação: a mudança tecnológica nos EUA no século XX. Campinas, SP: Editora da UNICAMP, 2005.

ORGANISATION FOR ECONOMIC CO-OPERATION AND DEVELOPMENT. A New Economy?: The Changing Role of Innovation and Information Technology in Growth. OECD Publishing, 2000.

ORGANIZATION FOR ECONOMIC COOPERATION AND DEVELOPMENT - OECD. Structural Adjustment and Economic Performance. Paris: Organization for Economic Cooperation and Development, 1987.

PALMA, J. G. Quatro fontes de desindustrialização e um novo conceito de doença holandesa. In: Conferência de Industrialização, desindustrialização e desenvolvimento. Federação das Indústrias do Estado de São Paulo, 2005.

PEREZ, C. Technological revolutions and techno-economic paradigms. Cambridge journal of economics, v.34, n.1, p.185-202, 2010.

PEREZ, Carlota. Techno-economic paradigms: essays in honour of Carlota Perez. Anthem Press, 2011.

ROWTHORN, R.; WELLS, J. R. De-industrialisation and Foreign Trade. Cambridge University Press, Cambridge. 1987

STURGEON, T. J. Modular Production Networks: A New American Model of Industrial Organization. Industrial and Corporate Change, v. 11, n. 3, p. 451- 496, 2002.

TREGENNA, F. Characterising deindustrialisation: An analysis of changes in manufacturing employment and output internationally. Cambridge Journal of Economics, v. 33, n. 3, p. 433-466, 2008.

UNITED NATIONS CONFERENCE ON TRADE AND DEVELOPMENT - UNCTAD. Trade and Development Report: Structural transformation for inclusive and sustained growth. United Nations: New York and Geneva, 2016. 